\title{
Influence of irrigants on coronal microleakage of adhesive restorative materials using polymicrobial marker
}

\author{
Sumalatha Chukkala ${ }^{1 *}$, Srikanth.Thammisetty ${ }^{2}$, Sivaram Penigalapati ${ }^{3}$, Balasaraswati Kudithi ${ }^{4}$, Karthik Basa ${ }^{.5}$ \\ ${ }^{1,4,5}$ Senior Lecturer, ${ }^{2}$ Lecturer, ${ }^{\mathbf{3}}$ Reader, ${ }^{\mathbf{1 , 3 , 4}}$ Dept. of Conservative Dentistry and Endodontics, ${ }^{\mathbf{5}}$ Dept. of Conservative Dentistry, ${ }^{\mathbf{1}} \mathrm{Meghna}$ \\ Institute of Dental Sciences, Nizamabad, Telangana, ${ }^{2}$ University of Rwanda, Kigali, Rwanda, ${ }^{3}$ Malla Reddy College of Dental Sciences, \\ Hyderabad, Telangana, ${ }^{4}$ C.K.S Teja Dental College of Science and Research, Tirupai, Andhra Pradesh, ${ }^{5}$ Panineeya Institute of Dental \\ Sciences and Research Centre Hyderabad, Telangana, India
}

\begin{abstract}
Objective: The objective was to evaluate and compare coronal microleakage of two different adhesive restorative cements placed in pulp chamber following different irrigant regimens by using polymicrobial marker.

Materials and Methods: Access opening of 60 single rooted teeth was done. Cleaning and shaping was done in a step down procedure using irrigation regimen for thirty samples as sodium hypochlorite and tublicid plus and other group with sodium hypochlorite and EDTA. All samples were sectioned horizontally $1 \mathrm{~mm}$ below the orifice and each group was again subdivided into two subgroups and restored with nano-composite and nano-glass-inomer cement and were artificially aged by thermocycling. Microleakage was evaluated by placing samples in a split chamber model and observed for turbidity in the lower chamber for a period of 90 days.

Results: Kruskal-Wallis one way ANOVA test and Chi-square test was done to statistically assess the effect of final irrigants on sealing ability of these restorative materials. It was found that there was no significant difference among the four groups.
\end{abstract}

Conclusion: Samples irrigated with tublicid plus and restored with nanocomposites showed better sealing ability than other three groups.

Keywords: Root canal irrigants, Coronal microleakage, Polymicrobial marker.

\section{Introduction}

The main aim of root canal treatment is to create a fluid tight impervious apical, lateral and coronal seal thus perpetuating the state of disinfection. This is to eliminate the risks of infection or re-infection of the pulp space system which would otherwise lead to percolation of periapical fluids, proteins, and bacteria through the root canal causing an inflammatory reaction periapically which ultimately lead to root canal failure. ${ }^{1}$

The literature indicates significant coronal dye and bacterial leakage following exposure of sealed root canals to artificial and natural saliva leading to complete bacterial leakage may occur within 2 days. $^{2}$ Supported in an invitro study, found that dye leakage can occur in as little as three (3) days. ${ }^{3}$

Sealing the endodontic access cavity successively or at endodontic session intervals is mandatory in order to prevent the canal from being contaminated by food debris, oral fluids, and microorganisms until the ultimate coronal restoration. ${ }^{4}$ Coronal leakage is considered as a negative contributor to prognosis of endodontic treatment than apical leakage. $^{5-7}$ Lack of adhesion and sealing between final restoration and tooth structure can permit movement of micro-organisms or their toxins along canal walls or through voids in root canal filling material to periapical tissues compromising prognosis of non surgical endodontic treatment. ${ }^{8}$ Smear layer produced during instrumentation acts as a barrier between adhesive and canal wall preventing resin penetration into the etched surface leading to compromised hybrid layer formation and thus hampering adequate seal of adhesive cement to tooth surface..$^{9,10}$

Smear layer is a combination of organic and inorganic components formed during root canal preparation. This layer consists of dentin debris, pulp remnants, bacteria, endotoxin and sometimes restorative materials. ${ }^{11}$ To achieve good bond between restoration and tooth, removal of the smear layer provides more efficient disinfection and improves the seal of root fillings due to penetration of sealer and restoration into the open dentinal tubules, decreasing microleakage. ${ }^{12,13}$

Various irrigants used for smear layer removal are citric acids, phosphoric acid, sodium hypochlorite, EDTA, EDTAC and Carbamide Peroxide. ${ }^{14}$ When used as an endodontic irrigant, EDTA has an efficient chelating action, dissolving mineralized tissues and promoting smear-free surfaces. To obtain a maximum cleansing effect after instrumentation, it is necessary to use chelating agents (EDTA) followed by a tissue solvent $(\mathrm{NaOCl})$ and final rinse with saline. ${ }^{15}$

But till to date no irrigants or restorative material could resist microleakage thus compromising prognosis of non surgical endodontic treatment. In this present study tublicid plus, an endodontic irrigant claimed to remove smear layer was used to see whether irrigation with tublicid plus might reduce microleakge.

\footnotetext{
*Corresponding Author: Sumalatha Chukkala, Dept. of Conservative Dentistry and Endodontics, Meghna Institute of Dental Sciences, Nizamabad, Telangana, India

Email: drsumalatha28@gmail.com

http://doi.org/10.18231/j.ijce.2019.023
} 
So the aim of the present study was to evaluate and compare coronal microleakage of two different adhesive restorative cements placed in pulp chamber following different irrigant regimens.

\section{Materials and Methods}

A total of 60 freshly extracted (Fig.1), intact human mandibular premolars were used in this study. The teeth were immersed in $3 \%$ Sodium hypochlorite for $15 \mathrm{~min}$ to dissolve organic tissue from the root surfaces and later stored in saline solution until the study was started. Using Endoaccess bur\#3, access opening was done in all teeth and patency was checked with k-file 15 . The coronal third of tooth was enlarged with Gates glidden drill \#4. The cusps of all teeth were flattened and the crown part of the tooth was selected for the study. 30 samples were irrigated with $2 \mathrm{ml}$ of $3 \%$ sodium hypochlorite and 17\% EDTA, finally rinsed with saline. For another 30 samples irrigation regimen was $2 \mathrm{ml}$ of 3\%sodium hypochlorite and tublicid plus, finally rinsed with saline. Coronal section of $4 \mathrm{~mm}$ length was used in this study which was obtained by sectioning tooth horizontally with diamond disk (Fig. 2). All the samples were prepared such that they have through and through channel and were coated with three layers of nail varnish and autoclaved.

Each group of 30 samples were again subgrouped into two subgroups such that each has 15 teeth $(n=15)$ and restored with nanocomposite and nano glass ionomer cement according to manufacturer instructions. (Fig. 3)

Group 1: $2 \mathrm{ml} 3 \% \mathrm{NaOCl}+$ saline rinse + EDTA + final rinse with saline and restored with nanocomposite.

Group 2: $2 \mathrm{ml} 3 \% \mathrm{NaOCl}+$ saline rinse + tublicid plus + final rinse with distilled water and restored with nanocomposite.

Group 3: $2 \mathrm{ml} 3 \% \mathrm{NaOCl}+$ saline rinse + EDTA + final rinse with saline and restored with nano glass ionomer cement.

Group 4: $2 \mathrm{ml} 3 \% \mathrm{NaOCl}+$ saline rinse + tublicid plus + final rinse with distilled water and restored with nano glass ionomer cement.

To artificially age teeth, all samples were subjected to thermocycling $\left(150\right.$ cycles at $5{ }^{\circ} \mathrm{C}$ and $55^{\circ} \mathrm{C}$ for dwell time of $30 \mathrm{sec}$ ). (Fig.4)

Several methods have been used to demonstrate the sealing ability of materials, but because of the limitations of dye, radioisotope, and pressure driven fluid transport methods, a bacterial challenge may provide a more accurate indicator of clinical applications and so a microbiological study was conducted. ${ }^{16}$

The samples were placed in an ependroff tubes and sealed with acrylic and feviquick such that small part of the tooth was suspended out of the ependroff tubes to be in contact with the sterile broth in a glass bottles of $100 \mathrm{cc}$ volume. Ependroff tubes with samples and glass bottles were autoclaved before subjecting them to microbiological study. Brain heart infusion broth inoculated with Enterococcus faecalis, Candida albicans for $24 \mathrm{hrs}$ and placed in the ependroff tubes and sterile brain heart infusion broth was placed in glass bottles. All the samples were placed in an incubator at $37{ }^{\circ} \mathrm{C}$ (Fig. 5) and for every 5days the brain heart infusion broth inoculated with Enterococcus faecalis, Candida albicans in ependroff tubes was replaced with fresh bacteria inoculated broth.

Upto 90days, every day the samples were observed for turbidity (Fig. 6) which was an visual indication for occurrence of microlekage (Fig. A,B). The day on which leakage occurred was noted. Results were statistically analyzed by kruskal-walis ANOVA test and Chi-square test.

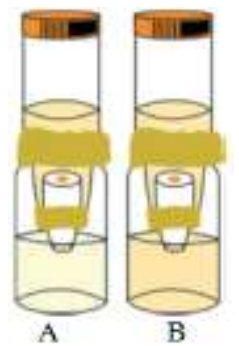

Fig. A - Apparatus set-up demonstrating fresh broth in lower chamber. B - Evident turbidity of broth in lower chamber after E.faecalis and Candida albicans penetration through the specimen

\section{Results}

Kruskal-Wallis one way ANOVA test and Chi-square test was done to statistically analyze the sealing ability of the restorative materials placed after smear layer removal by irrigating with different final irrigation solutions. It was observed that there was no significant difference among the four groups.

Sample irrigated with EDTA and restored with nanocomposite showed maxium leakage with mean number of days at which leakage occurred was 55.53 and minimum microleakage was seen with samples irrigated with tublicid plus and restored with nanocomposite with mean number of days at which leakage occurred was 70.75 .

\section{Discussion}

Microleakage is defined as clinically undetectable passage of bacteria, fluids, molecules or ions between a cavity wall and the restorative material applied to it. The integrity and durability of the marginal seal has always been of prime concern in the investigation of the performance of a dental restorative material. Clinically microleakage can be identified as a dynamic phenomenon.

Coronal leakage is considered as a negative contributor to prognosis of endodontic treatment. Today more attention has been focused on procedures performed to achieve an effective coronal seal soon after the completion of root canal therapy. ${ }^{8}$ Restoration of endodontically treated teeth with adhesive restoration permits transmission of functional stresses across the bonded interface to the tooth. ${ }^{17,18}$ For adhesive cement to bond to tooth structure, the adherend should be free from surface contaminants like smear layer which is produced during instrumentation and can be forced $1-5 \mathrm{~mm}$ into the dentinal tubules, to create a smear plug that 
reduces dentine permeability. This layer is acid labile and can be dissolved by fluids with $\mathrm{pH}$ between 6.0 and 6.8 . Some bacteria may degrade the smear layer via proteolytic enzymes that eliminate the collagen component rather than the hydroxyapatite component. Therefore, by acting as a substrate for bacterial growth, the smear layer is susceptible to bacterial penetration. ${ }^{19}$ Lack of adhesion and sealing between final restoration and tooth structure can permit movement of micro-organisms or their toxins along canal walls or through voids in root canal filling material to periapical tissues compromising prognosis of non surgical endodontic treatment. Hypersensitivity to thermal and osmotic stimuli occurs as a result of a compromised marginal seal causes hydrodynamic fluid movement through a degrading smear layer into the underneath patent dentinal tubules.

One of the desirable properties of irrigants is smear layer removal and demonstrated that canal surfaces without a smear layer permit penetration of filling materials into patent dentinal tubules, increasing the contact surface, improving mechanical retention and reducing the possibility of microleakage through the filled canal independent of the obturation technique..$^{20,21}$

The type of irrigant was found to positively reduce coronal microleakage. An ideal irrigants should be able to eliminate smear layer. ${ }^{22}$ To achieve these properties various root canal irrigants are used either singly or with combination.

In this study sodium hypochlorite, EDTA and tublicid plus were used because sodium hypochlorite is most popular and advocated irrigant has several properties that contribute to achieve chemical debridement of the root canal system like antibacterial and lubricant effect, and has the capability of dissolving tissue remnants and flushing out loose debris but it does not remove the smear layer from the dentin wall. Chelating agent solutions such as EDTA decalcify and soften dentin eliminating the smear layer. EDTA only removes the inorganic component of smear layer; therefore a proteolytic agent like $\mathrm{NaOCl}$ is utlisized for dissolving inorganic tissue. ${ }^{23}$ The advantage of this single mixture is that it has chelating as well as organic solvent action. This will prevent use of a large volume of combination solution to remove the smear layer. ${ }^{24}$

The combination of solutions such as ethylene diamine tetra-acetic acid (EDTA) and $\mathrm{NaOCl}$ is used to remove the smear layer from root canal walls. But the treatment with EDTA left a chelated layer of dentine at the dentine-root filling interface which may contribute additionally to ongoing demineralization, resulting in further increase of apical-leakage. Because of these limitations, a search for a better root canal irrigant is not stopping. ${ }^{25}$

Tublicid plus which has the same action of EDTA was used in this study to compare the efficacy of sealing ability of restoration after samples were irrigated according to manufacturer instructions.

In this study dual chamber model was used to ellict the microleakage of the restored samples by observing for turbidity in the lower chamber. Kruskal-Wallis one way ANOVA test and Chi-square test was done to statistically analyze the sealing ability of the restorative materials and was observed that there was no significant difference among the four groups in preventing coronal microleakage.

It was observed that samples irrigated with tublicid plus and restored with nanocomposites showed better sealing ability and least sealing ability was seen with group restored with samples irrigated with EDTA and restored with nano glass ionomer cement.

Table 1: Mean number of days at which the leakage occurred in each group

\begin{tabular}{|c|c|c|}
\hline Groups & $\begin{array}{c}\text { Mean no. } \\
\text { of days }\end{array}$ & $\begin{array}{c}\text { Std. } \\
\text { Dev. }\end{array}$ \\
\hline Ketac N100 with EDTA & 62.34 & 8.21 \\
\hline Nano composite with EDTA & 55.53 & 12.24 \\
\hline Ketac N100 with Tublicid plus & 56.56 & 4.85 \\
\hline Nano composite with Tublicid plus & 70.75 & 7.54 \\
\hline Total & 61.84 & 10.67 \\
\hline F-value & 6.8574 & \\
\hline P-value & $0.0009^{*}$ & \\
\hline
\end{tabular}

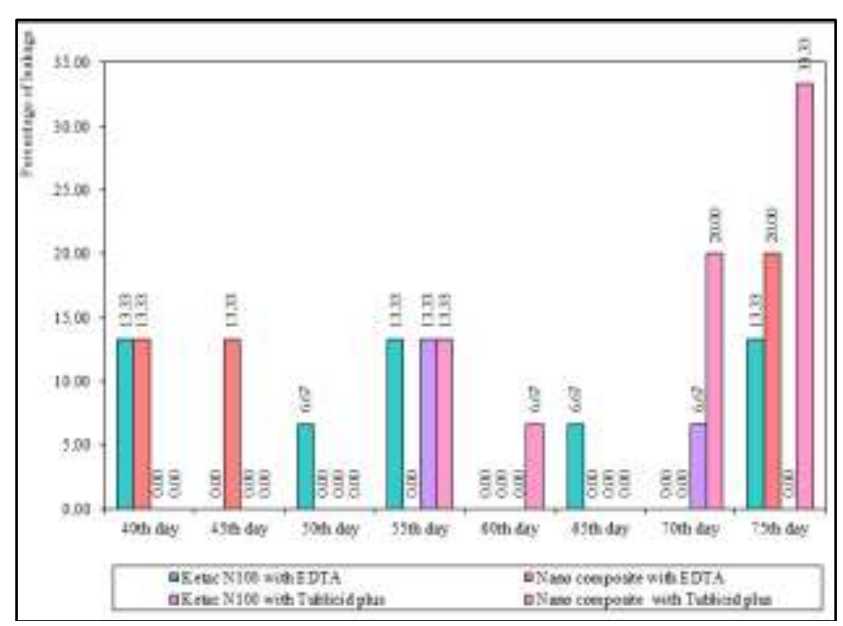

Fig.: Comparison of time points with respect to leakage in Conventional glass ionomer, Micro composite (Z250), Ketac N100 and Nano composite

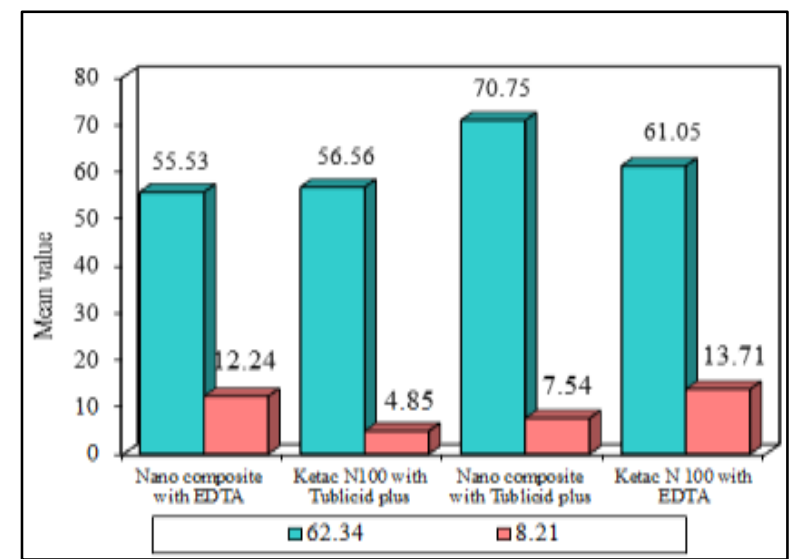

Fig.: Comparison of mean number of days at which the leakage occurred in each group 


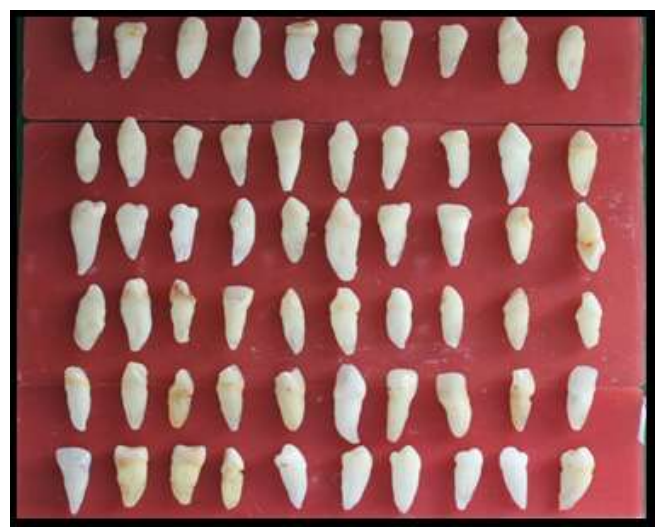

Fig. 1: Freshly extracted human mandibular premolars

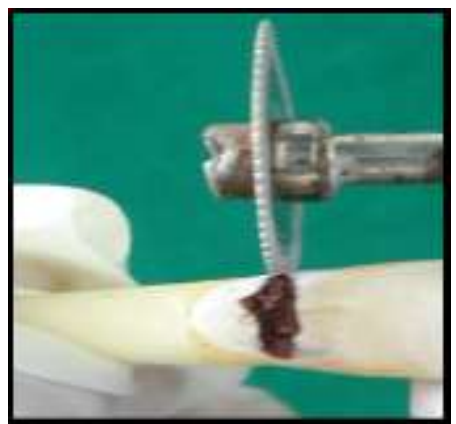

Fig. 2: Coronal section of $4 \mathrm{~mm}$ length
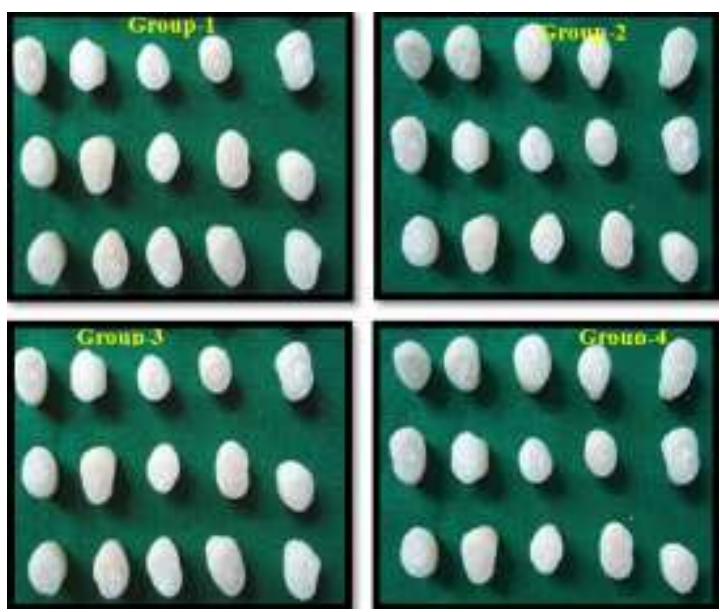

Fig. 3: Restored samples

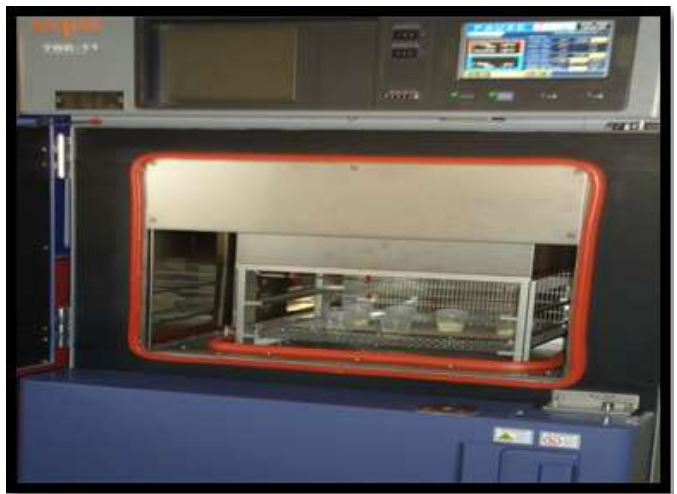

Fig. 4: Thermocycling restored samples

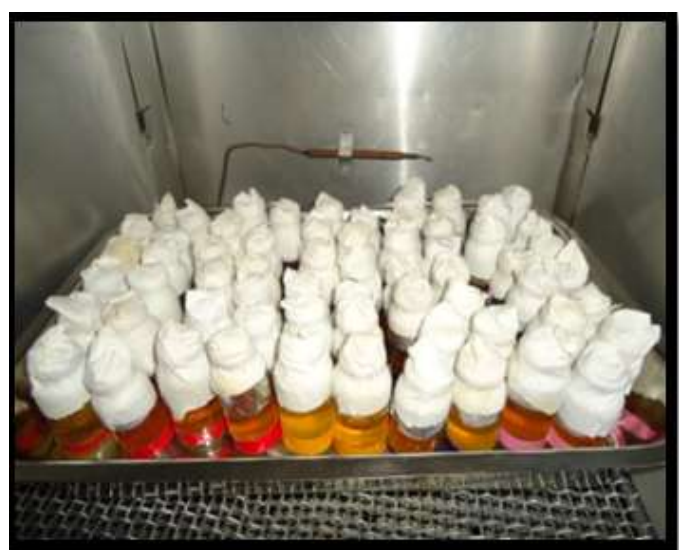

Fig. 5: Samples in incubator
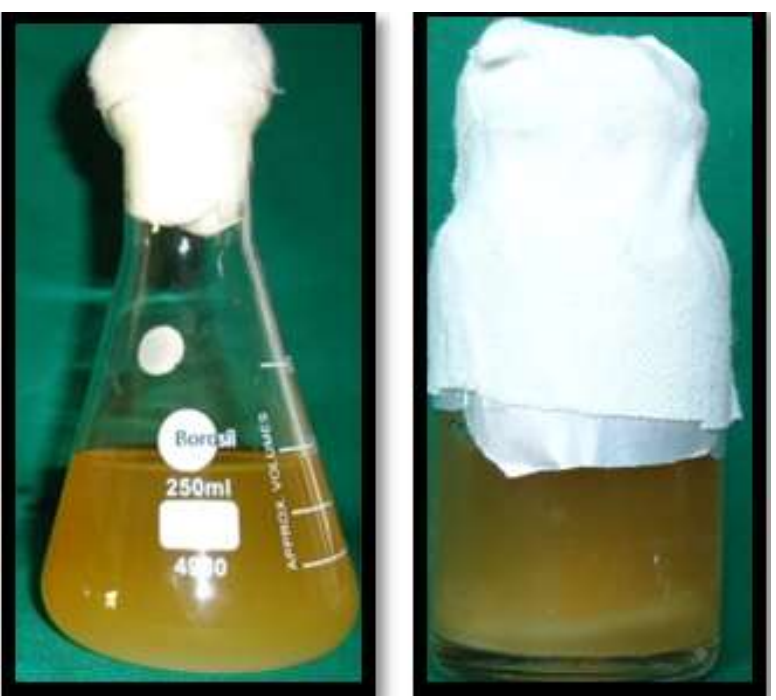

Fig. 6: Turbidity in lower chamber similar to bacteria incubated brain heart infusion broth

\section{Conclusion}

From this present study, I conclude that no material can replace lost tooth structure. Either the irrigants or the restorative materials could not effectively prevent microleakage. From this study i infer that immediately after completion of endodontic treatment, definitive treatment like placing crowns should be done without fail which would otherwise compromise the success of the endodontic treatment.

\section{Source of Funding}

None.

\section{Conflict of Interest}

None.

\section{References}

1. Siqueira JF Jr, Rocas IN, Lopes HP, de Uzeda M. Coronal leakage of two root canal sealers containing calcium hydroxide after exposure to human saliva. J Endod 1999;25:14-16.

2. Khayat A, Lee SJ, Torabinejad M.: Human saliva penetration of coronally unsealed obturated root canals. J Endod 1993;19(9):458-61. 
3. Swanson K, Madison S.: An evaluation of coronal microleakage in endodontically

4. treated teeth. Part I. Time periods. J Endod 1987;13(2):56-9.

5. Grossman LI, Suresh Chandra B, Gopi Krishna V, editors. Endodontic practice. 12thed. New Delhi: Wolters Kluwer Press; 2010: 278-307.

6. Madison S, Wilcox LR. An evaluation of coronal microleakage in endodontically trented teeth: Part III. In vivo study. J Endod 1988;14(9):455-8.

7. Magura Me, Kafrawy AH, Brown CE Jr and Newton CW. Human saliva cornal microleakage in obturalted root canals: An invitro study. J Endod 1991;17(7):324-31.

8. Sritharan A.: Discuss that the coronal seal is more important than the apical seal for endodontic success. Aust Endod $J$ 2002;28(3):112-5.

9. Galavan RR Jr, West LA, Leiwhr FR, Pashely DH. Coronal microleakage of five materials used to create an intracoronal seal in endodontically treated teeth. $J$ Endod 2002;28:59-61.

10. Kennedy WA, Walker WA 3rd, Gough RW. Smear layer removal effects on apical leakage. J Endod 1986;12:21-7.

11. Vassiliadis L, Liolios E, Kouvas V, Economides N. Effect of smear layer on coronal microleakage. Oral Surg Oral Med Oral Pathol Oral Radiol Endod 1996;82:315-20.

12. Gale MS. Coronal microleakage. Ann R Australas Coll Dent Surg 2000;15:299-305.

13. McComb D, Smith DC. A preliminary scanning electron microscopic study of root canals after endodontic procedures. $J$ Endod 1975;1:238-42.

14. Pashley DH. Smear layer: overview of structure and function. Proc Finn Dent Soc 1992;88:215-24.

15. Torabinejad M, Handysides R, Khademi AA, Bakland LK. Clinical implications of the smear layer in endodontics: a review. Oral Surg Oral Med Oral Pathol Oral Radiol Endod 2002;94:658-66.

16. Yamada RS, Armas A, Goldman M, Lin PS () A scanning electronmicroscopic comparison of a highvolume canal flush with several irrigating solutions.Part3. J Endod 1983;9:137-42.
17. Pommel L, Jacquot B, Camps J. Lack of correlation among three methods for evaluation of apical leakage. J Endod 2001;27:347-50.

18. Eakle WS. Fracture resistance of teeth restored with class II bonded composite resin. J Dent Res 1986;65:149-53.

19. Douglas WH. Clinical status of dentin bonding agents. J Dent 1989;17:209-15.

20. Pashley DH. Clinical considerations of microleakage. J Endod 1990;16:70-7.

21. White RR, Goldman M, Lin PS. The influence of the smeared layer upondentinal tubule penetrationby plastic filling materials. J Endod 1984;10;558-62.

22. CergneuxM, Ciucchi B, Dietschi JM, Holz J () The influence of smear layer onthe sealing abilityof canal obturation. Int Endod J 1987;20:228-32.

23. Goldberg F, Abramovich A. Analysis of the effect of EDTAC on the dentinal walls of the root canals. J Endod 1977;3:101-5.

24. Torabinejad M, Cho Y, Khademi AA, Bakland LK, Shabahang $\mathrm{S}$. The effect of various concentrations of sodium hypochlorite on the ability of MTAD to remove the smear layer. J Endod 2003;29:233-9.

25. Bekir Oguz Aktenes, Ugur Bilkay. Smear layer removal with different concentration of EDTA ethylene diamine mixture. JOE 1993:19:5:228-31.

26. Dogan.H, Calt.S. Effect of chelating agents and sodium hypochlorite on mineral content of root dentin. $J$ Endod 2001;27:578-80.

How to cite this article: Chukkala $S$, Thammisetty $S$, Penigalapati S, Kudithi B, Basa K. Influence of irrigants on coronal microleakage of adhesive restorative materials using polymicrobial marker. Indian J Conserv Endod 2019;4(3):96100. 